\title{
Tat-functionalized liposomes for the treatment of meningitis: an in vitro study
}

\author{
This article was published in the following Dove Press journal: \\ International Journal of Nanomedicine \\ 12 April 2017 \\ Number of times this article has been viewed
}

\author{
Caterina Bartomeu \\ Garcial,* \\ Di Shi ${ }^{2, *}$ \\ Thomas J Webster ${ }^{2}$ \\ 'Department of Chemical Engineering, \\ Universitat Rovira i Virgili, Tarragona, \\ Spain; ${ }^{2}$ Department of Chemical \\ Engineering, Northeastern University, \\ Boston, MA, USA \\ *These authors contributed equally \\ to this work
}

\begin{abstract}
Bacterial meningitis has become a global concern, because of the emergence of antibiotic-resistant bacteria. It has been demonstrated that liposomes can enter bacteria, thus providing a possible treatment for numerous infections, including meningitis. Fusogenic liposomes are $\mathrm{pH}$-sensitive with a high capacity to fuse with the bacteria membrane and promote intracellular drug release. Moreover, this ability can be improved by using cell-penetrating peptides (such as Tat $_{47-57}$, which is a peptide derived from the Tat protein of HIV). The purpose of this in vitro study was to demonstrate for the first time the ability of the presently prepared fusogenic liposomes, which were spherical particles with a diameter of $100 \mathrm{~nm}$ loaded with antibiotics and functionalized with-cell penetrating peptides ( $\mathrm{Tat}_{47-57}$ ), to fight the main bacteria that cause meningitis. For this, vancomycin, methicillin, and ampicillin antibiotics were loaded inside fusogenic liposomes to fight Streptococcus pneumoniae, methicillin-resistant Staphylococcus aureus, and Escherichia coli. Antibacterial activity of Tat-functionalized and nonfunctionalized liposomes loaded with antibiotics was tested by determining bacteria colony-forming units and growth-curve assays coupled with live/dead assays using fluorescence microscopy. Results showed a remarkable decrease in antibiotic minimum inhibitory concentration when all of the bacteria were treated with these novel liposomes, especially for the functionalized liposomes loaded with methicillin. With antibiotic concentrations of $1.7-3 \mu \mathrm{g} / \mathrm{mL}$ for Tat-functionalized liposomes loaded with methicillin, the bacteria population was totally eradicated. Cytotoxicity tests with astrocytes and endothelial cells, major cellular components of the blood-brain barrier, were also performed for all of the liposomes, including free antibiotic and the Tat peptide. Results showed much promise for the further study of the presently formulated liposomes to treat meningitis.
\end{abstract}

Keywords: fusogenic liposomes, cell-penetrating peptides, minimum inhibitory concentration, $\mathrm{MIC}$, bacteria colony-forming units, fluorescence microscopy, cytotoxicity

\section{Introduction}

Brain-inflammatory diseases (such as meningitis) are among the top ten infections that cause death. Bacterial meningitis, the most common, is mainly caused by Streptococcus pneumoniae (Gram-positive) and Neisseria meningitidis (Gram-negative) bacteria. In the past few years, numerous cases of drug-resistant bacteria have been reported, including ones that refer to the two aforementioned bacteria. ${ }^{1}$ Biofilms are one of the major forms in which bacteria are present during an infection, as they are matrixenclosed, complex, and differentiated communities of bacteria that adhere to a surface and form dense bacterial clusters. ${ }^{2}$ These biofilms pose large challenges for the medical community, as they are able to respond to environmental changes and threats, becoming resistant to many different drugs.

The use of nanotechnology in medicine, especially in drug delivery, is one of the most promising strategies to solve this problem. Polymers, antimicrobial peptides,
Correspondence: Thomas J Webster Department of Chemical Engineering, Northeastern University, 360 Huntington Avenue, Boston, MA 02115, USA

Tel +l 6173736585

Email th.webster@neu.edu 
nanoparticles, and liposomes, among other techniques, have been studied to combat these new drug-resistant microbes. Some of these novel particles can be used as carriers for an antibacterial agent, such as liposomes and polymers, ${ }^{3,4}$ and others have their own antibacterial properties, such as silver nanoparticles and antimicrobial peptides. ${ }^{5,6}$ With adequate functionalization, these particles are able to attach themselves to the bacteria membrane, breaking the membrane or fusing with it in order to introduce the antibacterial agent they carry inside.

Liposomes, made preferentially of phospholipids, have the ability to form structures with barrier properties separating the interior of the vesicles from the outside medium. ${ }^{7}$ If these properties are taken advantage of, it is possible to load antibiotics inside liposomes and make them qualified drug carriers. In addition, they are considered biodegradable and nontoxic, which are critical properties for in vivo drug delivery.

Liposomes containing lipids that can promote destabilization of bacteria membranes at certain environmental conditions (such as acidic $\mathrm{pH}$ ) are called fusogenic liposomes or $\mathrm{pH}$-sensitive liposomes. One of the well-known examples is liposomes incorporated with the phosphoethanolamine (PE) moiety, such as 1,2-dioleoyl-sn-glycero-3-PE (DOPE). ${ }^{8-11}$ Some studies also present the capacity of these types of liposomes to support the penetration of antibiotics across the outer membrane (OM) of Gram-negative bacteria. ${ }^{12}$ There are two options for the antibiotics to cross the OM: 1) hydrophilic antibiotics that diffuse through porin channels, which are open water-filled channels that govern penetration though the OM, and 2) hydrophobic compounds that enter by a passive route. The structure of these porins depends on the type, size, and functional structure of the bacteria. Some antibiotics with high molecular weight are unable to pass through these porins. One of these antibiotics is vancomycin, which inhibits the synthesis of peptidoglycans, which are a major component of bacteria.

The possibility of encapsulating vancomycin inside a fusogenic liposome was studied by Nicolosi et al. ${ }^{11}$ By using a DOPE-dipalmitoylphosphatidylcholine (DPPC)-cholesteryl hemisuccinate (CHS) lipid mixture, they produced $\mathrm{pH}-$ sensitive liposomes that were able to interact and fuse with the bacterial cell membrane. Liposomes made with DPPC and dimyristoylphosphatidylglycerol and loaded with tobramycin were also tested with Gram-positive bacteria, obtaining promising results that consisted of a decrease in minimum inhibitory concentration (MIC) in comparison with free antibiotic delivery. For $S$. aureus, bacteria growth was reduced 566-fold in cultures treated with the encapsulated antibiotic in comparison with the free antibiotic. The association of DOPE with CHS has been shown to provide vesicles with $\mathrm{pH}$-dependent stability that promotes the selective fusion of liposomes with specific cell components. DOPE is used to increase the lipophilicity of the liposomal membrane and reduce the energy of the interaction of the lipid bilayer. DPPC is used to achieve a stable liposomal bilayer. Nevertheless, the selective fusion of liposomes with bacteria can be affected by the presence of eukaryotic cells and tissues, due to the presence of similar cell components between both types of cells. With the correct functionalization, the affinity of liposomes for specific bacteria components could increase, as well as the circulation time of these particles to reach the target sites. In addition, fusogenic liposomes can be functionalized with many types of ligands to improve their antimicrobial activity. For example, in order to pass the blood-brain barrier and treat brain diseases and infections, cell-penetrating peptides are often incorporated onto the liposome surface. Among all kinds of cell-penetrating peptides, Tat (YGRKKRRQRRR) is a peptide sequence that presents a relatively high permeability through the blood-brain barrier at $4 \mu \mathrm{L} /(\mathrm{g} \times \mathrm{min}) .{ }^{13}$ This remarkable result makes this cell-penetrating peptide a good candidate to combat brain bacterial infections.

In consideration of all these factors, the goal of this in vitro project was to demonstrate the ability of Tat-functionalized fusogenic liposomes loaded with an antibiotic to fight the main bacteria that cause meningitis, and thus determine their potential future use as a novel treatment for this disease. As such, functionalized liposomes were synthesized and loaded with antibiotics to combat S. pneumoniae, one of the main bacteria that cause bacteria meningitis. Moreover, they were also tested with other types of general bacteria, such as methicillin-resistant $S$. aureus (MRSA), which can also cause meningitis, depending on the age of the person and if that person has suffered any head trauma. ${ }^{14}$ Escherichia coli was also tested.

The synthesized liposomes were characterized using transmission electron microscopy (TEM). The inhibitory effect on bacteria growth of the liposomes was compared with free-antibiotic and nonfunctionalized liposomes by generating growth curves, colony-forming units, and live/dead assays. Simultaneously, cytotoxicity assays were performed to ensure that the liposomes did not pose a threat to normal healthy mammalian cells in the blood-brain barrier.

\section{Materials and methods}

For liposome synthesis, DOPE, CHS, DPPC, and 1,2distearoyl-sn-glycero-3-PE- $N$-(maleimide[polyethylene 
glycol]-2000) (DSPE-DSPE-PEG ${ }_{2000}$-MAL) were purchased from Avanti Polar Lipids (Alabaster, AL, US). The Tat peptide (Cys-Tyr-Gly-Arg-Lys-Lys-Arg-Arg-Gln-ArgArg-Arg- $\mathrm{NH}_{2}$ ) was purchased from GenScript (Piscataway, NJ, US).

Dulbecco's Modified Eagle's Medium (DMEM), fetal bovine serum, poly-D-lysine vented cap flask, tissue- and nontissue-treated 96 well plates, chloroform, methanol, diethyl ether, trimethylamine, phosphate-buffered saline (PBS), propidium iodide, ampicillin, vancomycin, and methicillin were all purchased from Sigma-Aldrich (St Louis, MO, US). For the cytotoxicity assay, mouse brain endothelial cells (BEND3, CRL2299) and astrocytes (C8D1A, CRL2541) were purchased from the American Type Culture Collection (ATCC; Manassas, VA, US). Blood agar (Tryptic Soy Agar [TSA] plates with 5\% sheep blood) plates for bacterial culture and $\mathrm{SYTO}^{\circledR}$ stain for live-dead assays were purchased from Thermo Fisher Scientific (Waltham, MA, US).

S. pneumoniae (Klein) Chester (6303), multidrug-resistant E. coli (25922), and MRSA (43360) where purchased from ATCC. Brain-heart infusion broth for $S$. pneumoniae cultures was purchased from Sigma-Aldrich. For the MTS assay, the kit used was a Promega CellTiter 96 Aqueous One solution cell-proliferation assay purchased from Thermo Fisher Scientific.

\section{Preparation of Tat-functionalized liposomes}

The Tat peptide (1.5 eq) was reacted with DSPE-PEG ${ }_{2000^{-}}$ MAL (1 eq) in a chloroform/methanol solution $(\mathrm{v} / \mathrm{v}=2: 1)$, containing trimethylamine ( $2 \mathrm{eq})$, under an $\mathrm{N}_{2}$ atmosphere at room temperature for 30 hours. Thin-layer chromatography was used to observe the disappearance of DSPE-DSPEPEG $_{2000}-\mathrm{MAL}$, confirming that DSPE-DSPE-PEG ${ }_{2000}$-Tat was formed. ${ }^{15}$ The mixture was evaporated in a vacuum and the resulting thin film hydrated in PBS ( $\mathrm{pH} 7.4)$. Then, the excess Tat was removed by centrifuging the sample using filter tubs. The collected sample was vacuum-dried again and extracted by chloroform twice to purify the sample, and the final product was stored at $-20^{\circ} \mathrm{C}$ until further usage. A bicinchoninic acid assay was also performed on the sample to assure that the Tat peptide was successfully attached to DSPE-DSPE-PEG ${ }_{2000}$.

\section{Preparation of liposomes loaded with antibiotics}

The liposomes were formulated using the thin-lipid filmrehydration technique. Lipids (DOPE:DPPC:CHS:PEG at 40\%:15\%:35\%:10\% molar ratio) were first dissolved in chloroform. In the case of liposomes functionalized with Tat, DOPE:DPPC:CHS:PEG-Tat was used in the same proportion (40\%:15\%:35\%:10\% molar ratio). The solution was vacuum-dried and the formed thin-lipid film rehydrated with PBS containing various antibiotics to form the liposomes. Specifically, the antibiotic was first diluted in PBS (pH 7.4) with a desired concentration. Then, the lipid film and the antibiotic solution were sonicated for 5 minutes, followed by extrusion using $200 \mathrm{~nm}$ membrane filters. For producing plain liposomes that contained no antibiotics, the same procedure was carried out, except that PBS was used instead of antibiotics. Once obtained, dialysis was performed over 48 hours to eliminate excess antibiotics.

The loading efficiency of antibiotics in the aqueous solution was measured by spectrophotometry, as previously described. ${ }^{16-18}$ The loading efficiency of all the particles was calculated to be $80 \%-87 \%$ for the Tat-functionalized and nonfunctionalized liposomes loaded with vancomycin, 65\%-72\% with methicillin, and 71\%-74\% with ampicillin.

\section{Transmission electron microscopy}

To characterize the liposomes, TEM images were taken with a JEM-1010 (JEOL, Tokyo, Japan) of all the samples prepared, using phosphotungstic acid as the stain.

\section{Growth-curve assays}

Bacteria were cultivated overnight inside the incubator at $37^{\circ} \mathrm{C}$; S. pneumoniae was cultivated with brain-heart infusion broth, while MRSA was cultivated with trypticase soy broth. Then, optical density (OD) was checked with an absorbance plate reader (SpectraMax M3; Molecular Devices, Sunnyvale, CA, US) at $\mathrm{OD}_{600}$. Values around 0.5-0.7 were expected from MRSA for starting the growth-curve assay, while for $S$. pneumoniae it was around 0.1 .

The bacteria were seeded in a 96-well plate and different concentrations (for vancomycin, $0.2,0.3,0.7$, and $1 \mu \mathrm{g} / \mathrm{mL}$; for methicillin, $0.9,1.7,3.3$, and $5 \mu \mathrm{g} / \mathrm{mL}$; for ampicillin, $1,10,33$, and $50 \mu \mathrm{g} / \mathrm{mL}$ ) of antibiotics, liposomes loaded with antibiotics, or Tat-functionalized liposomes loaded with antibiotics were added to determine the MIC of each substance. Once the plate was prepared, the absorbance of all the samples was measured at $600 \mathrm{~nm}$ using an absorbance plate reader (SpectraMax) for 24 hours.

\section{Colony-counting assays}

Bacteria were seeded in a 96 well plate treated with different concentrations (vancomycin $0.2,0.6,1$, and $1.8 \mu \mathrm{g} / \mathrm{mL}$; methicillin $1,1.7,3.3$, and $5 \mu \mathrm{g} / \mathrm{mL}$ ) of antibiotic and Tat-functionalized liposomes loaded with antibiotics for 
8 hours inside an incubator at $37^{\circ} \mathrm{C}$. Then, the 96 -well plate was removed from the incubator and all samples diluted in a series of vials to $100 \times, 1,000 \times$, and $10,000 \times$. Three drops of $10 \mu \mathrm{L}$ of each dilution were placed in each agar plate (blood agar plates for S. pneumoniae and TSA plates for MRSA), and then they were incubated for 8 more hours inside the incubator at $37^{\circ} \mathrm{C}$, after which the colonies that had formed were counted.

\section{Live/dead bacterial viability assays}

A live/dead BacLight ${ }^{\mathrm{TM}}$ bacterial viability kit (Thermo Fisher Scientific) was used to evaluate bacterial viability after liposome treatment. Tat liposomes loaded with vancomycin at a concentration of $0.6 \mu \mathrm{g} / \mathrm{mL}$ were used to treat $S$. pneumoniae, and Tat liposomes loaded with methicillin at a concentration of $2 \mu \mathrm{g} / \mathrm{mL}$ were used to treat MRSA. The bacteria were first incubated with various samples in the same condition as the colony-counting procedure for 8 hours. SYTO 9 dye and propidium iodide were first mixed in $0.85 \% \mathrm{NaCl}$, and the as-mixed solution was used to stain the bacteria for 15 minutes. Fluorescence microscopy was used to obtain the images.

\section{In vitro cytotoxicity assays}

Cytotoxicity assays were performed with astrocytes and endothelial cells. First, they were cultured in complete media (DMEM with $10 \%$ fetal bovine serum and $1 \%$ penicillinstreptomycin) separately in a flask at $37^{\circ} \mathrm{C}$ in a humidified incubator with $5 \% \mathrm{CO}_{2}$. Then, cells were seeded in a 96-well plate at 5,000 cells/well in $100 \mu \mathrm{L}$ of cell medium and incubated for 24 hours at $37^{\circ} \mathrm{C}$ in a $5 \% \mathrm{CO}_{2}$ humidified atmosphere. The culture medium was then replaced with $100 \mu \mathrm{L}$ of freshly prepared culture medium containing different concentrations of antibiotics and functionalized liposomes loaded with antibiotics. The plate was cultivated again for 24 hours in the same environmental conditions as before. The culture media was removed again and replaced with $20 \mu \mathrm{L}$ of an MTS solution at 1:5 dilution in fresh media $(20 \mu \mathrm{L}+100 \mu \mathrm{L}$ DMEM). This time, the well plate was cultivated for just 4 hours to allow for a color change. Then, absorbance was measured at $490 \mathrm{~nm}$ under an absorbance plate reader (SpectraMax). Data were expressed as percentage of cell viability.

\section{Statistical analysis}

Each experiment was conducted at least three times, for two samples in each group. Data are presented as mean with standard error of the mean, and two-tailed Student's $t$-tests were used to evaluate differences between means, with a value of $P<0.05$ considered statistically significant.

\section{Results and discussion Transmission electron microscopy}

No significant differences were observed between the different liposomes. TEM images can be used to confirm the correct shape of liposomes, but not for demonstrating the presence of the Tat peptide nor for the loaded antibiotic, due to their small size and location, respectively (Figure 1).

In a previous study, it was observed that by loading vancomycin inside particles, liposomes became larger. ${ }^{19}$ In our study, this was not observed. A possible explanation could be that during the sizing process, only smaller particles passed through the filter. Similar images and results were obtained for the liposomes loaded with methicillin and ampicillin.

\section{Antibacterial activity assays}

\section{S. pneumoniae}

By comparing the antibacterial effect of each liposome group at the same concentration of antibiotic, it was observed that in almost every case, nonfunctionalized liposomes inhibited S. pneumoniae growth. Impressively, at the highest concentration tested, $1 \mu \mathrm{g} / \mathrm{mL}$, the Tat-functionalized liposomes completely inhibited S. pneumoniae growth, while with the
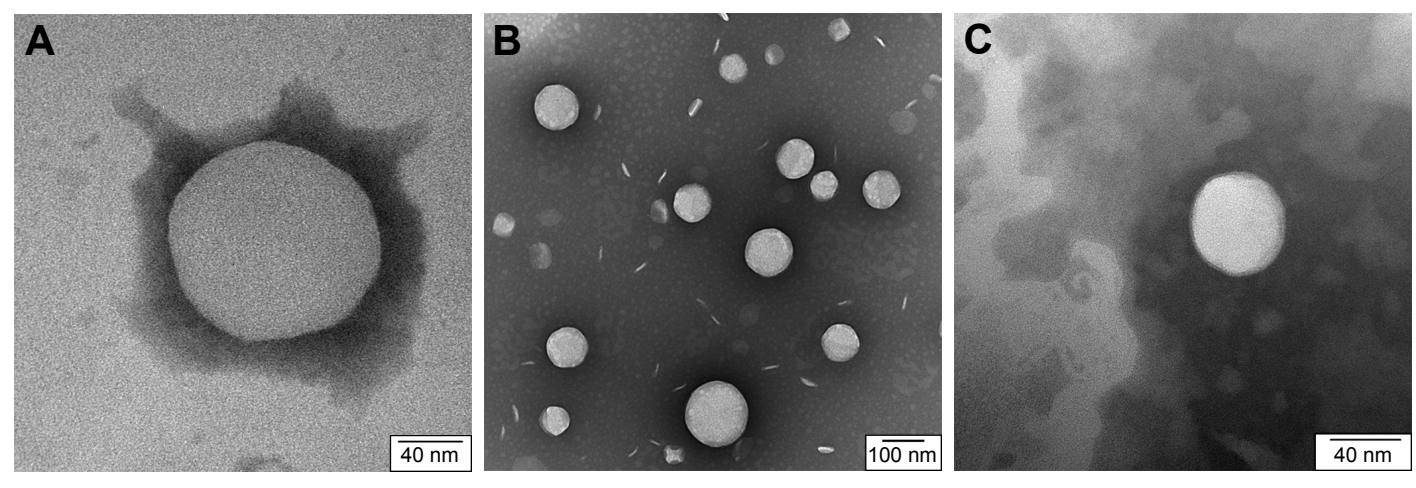

Figure I Transmission Electron Microscopy.

Notes: (A) Plain liposome; (B) liposomes loaded with vancomycin; (C) Tat-functionalized liposome loaded with vancomycin. 

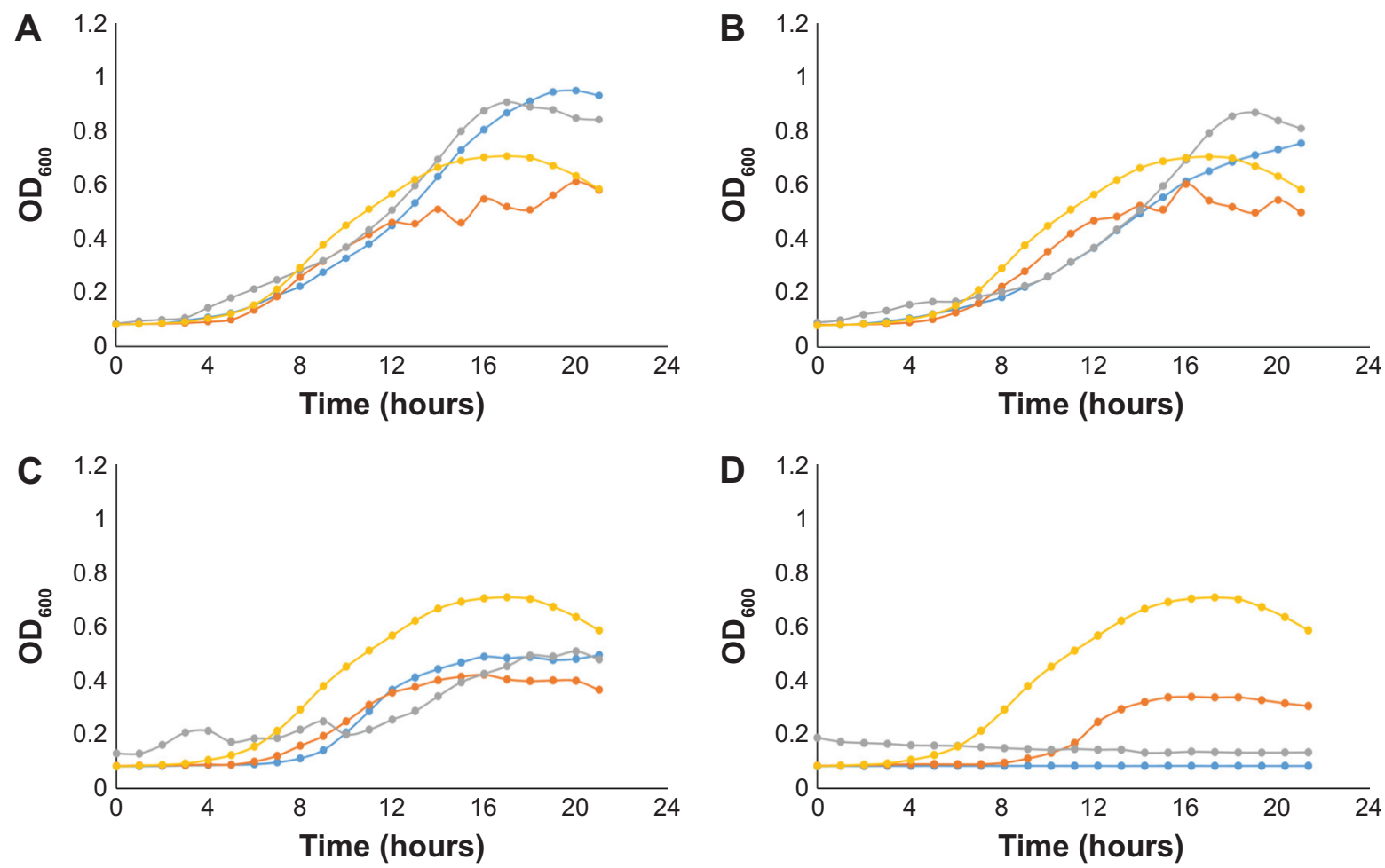

$$
\rightarrow \text { Van } \rightarrow \text { LipoVan } \rightarrow \text { Tat-LipoVan } \rightarrow \text { Control }
$$

Figure 2 Streptococcus pneumoniae treated with Van, Tat-LipoVan, and LipoVan.

Notes: Antibiotic concentrations of $(\mathbf{A}) 0.2 \mu \mathrm{g} / \mathrm{mL}$, (B) $0.3 \mu \mathrm{g} / \mathrm{mL}$, (C) $0.7 \mu \mathrm{g} / \mathrm{mL}$, and (D) I $\mu \mathrm{g} / \mathrm{mL}$. Data presented as means ( $\mathrm{n}=3$ ). Abbreviations: Van, vancomycin; Tat-LipoVan, Tat-functionalized Van-loaded liposomes; OD, optical density.

nonfunctionalized liposomes, some bacteria growth was observed.

The Tat-functionalized liposomes and free vancomycin presented similar antibacterial activity, as can be seen in Figure 2. However, it is important to note that these functionalized liposomes provide a better option for clinical treatment, as they possess lower cytotoxicity than the free antibiotic. It is also expected that the functionalized liposomes should reduce antibacterial resistance due to Tat targeting.

In a previous in vivo study where liposomes were loaded with an antibiotic to fight the same bacteria, ${ }^{20}$ the results showed that the liposomes promoted a significant concentration of antibiotics at the region where the bacteria where located, but reached similar efficiency for fighting bacteria. The use of Tat-functionalized liposomes to inhibit S. pneumoniae has not been reported previously, and results of this study demonstrate much promise for this approach.

To quantify the OD measurements, the modified Gompertz model was used:

$$
y=\mathrm{A} \cdot e^{-e\left(\frac{\mu \cdot e}{\mathrm{~A}}\right) \cdot(\lambda-t)+1}
$$

where $\mathrm{A}$ is the asymptote, $\mu$ the maximum exponential growth rate, $\lambda$ the lag time, and $t$ the time. Understanding the asymptote as the maximum value that the growth curve reaches, Table 1 shows that the lowest values for each antibiotic concentration were achieved by nonfunctionalized

\begin{tabular}{|c|c|c|c|c|c|c|c|c|c|}
\hline \multirow[t]{2}{*}{$\mu \mathrm{g} / \mathrm{mL}$} & \multicolumn{3}{|c|}{ Asymptote } & \multicolumn{3}{|c|}{$\begin{array}{l}\text { Maximum exponential growth } \\
\text { rate }(\mu) \text {, hours }\end{array}$} & \multicolumn{3}{|c|}{ Lag time $(\lambda)$, hours } \\
\hline & Van & LipoVan & Tat-LipoVan & Van & LipoVan & Tat-LipoVan & Van & LipoVan & Tat-LipoVan \\
\hline 0.2 & 0.95 & 0.61 & 0.91 & 0.074 & 0.055 & 0.082 & 5.46 & 3.46 & 5.53 \\
\hline 0.3 & 0.76 & 0.6 & 0.87 & 0.053 & 0.062 & 0.075 & 4.91 & 4.4 & 6.95 \\
\hline 0.7 & 0.5 & 0.42 & 0.49 & 0.042 & $0.05 \mathrm{I}$ & 0.064 & 6.55 & 5.02 & 6.05 \\
\hline I & 0.08 & 0.34 & 0.19 & 0 & 0.044 & 0 & - & - & - \\
\hline
\end{tabular}

Table I Different parameters calculated for the growth-curve model for Streptococcus pneumoniae

Abbreviations: Van, vancomycin; Tat-LipoVan, Tat-functionalized Van-loaded liposomes. 


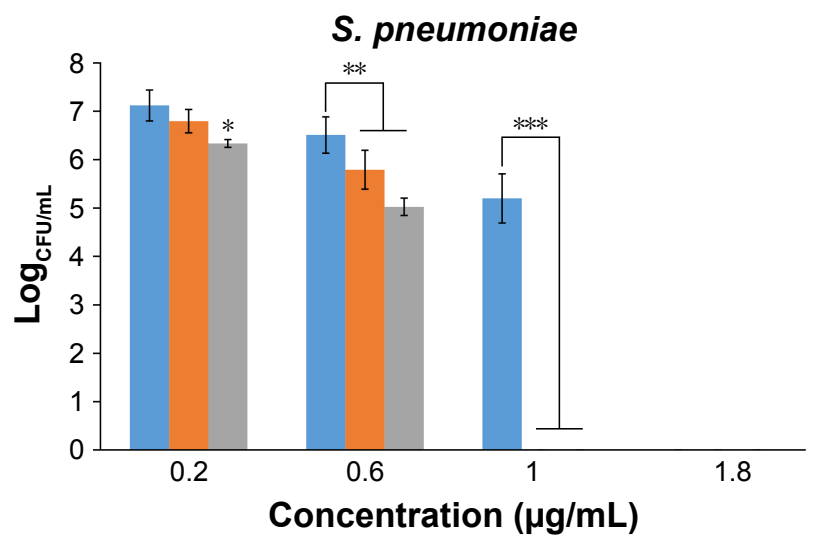

Vancomycin LipoVan Tat-LipoVan

Figure 3 Colony-forming units (CFU) of Streptococcus pneumoniae after treatment with free Van, LipoVan, and Tat-LipoVan for 8 hours.

Notes: $* P<0.05$ versus free $\operatorname{Van}$ and LipoVan $(0.2 \mu \mathrm{g} / \mathrm{mL})$; $* * P<0.05$ versus free Van $(0.6 \mu \mathrm{g} / \mathrm{mL}) ; * * * P<0.05$ versus free $\operatorname{Van}(I \mu \mathrm{g} / \mathrm{mL})$.

Abbreviations: Van, vancomycin; Tat-LipoVan, Tat-functionalized Van-loaded liposomes.

liposomes, which means that these were the particles that presented more bacteria-growth inhibition. For maximal exponential growth rate, the values were similar for all the samples, even though for most of the cases, values were lower for free vancomycin. With regard to the lag time, the values obtained were again similar for all the samples, demonstrating that there was no remarkable log-phase delay caused by the use of functionalized or nonfunctionalized liposomes.

The colony-forming unit results were much more favorable for the use of liposomes and Tat-functionalized liposomes. As can be seen in Figure 3, there were significant statistical decreases in bacteria for each formulation with increasing concentrations. Table 2 shows the values of colony-forming units $(\mathrm{CFU}) / \mathrm{mL}$ for each concentration and particle type.

For results obtained with antibiotic concentrations of 0.2 and $0.3 \mu \mathrm{g} / \mathrm{mL}$, for free vancomycin, the bacteria population decreased by $76 \%$, but for functionalized and nonfunctionalized liposomes, the decrease was much more severe $-96 \%$ and $90 \%$, respectively - which demonstrated

Table 2 Colony-forming units (CFU) for particles and concentrations

\begin{tabular}{llll}
\hline$\mu \mathrm{g} / \mathrm{mL}$ & CFU $/ \mathrm{mL}$ & & \\
\cline { 2 - 4 } & Free Van & LipoVan & Tat-LipoVan \\
\hline 0.2 & $1.32 \times 10^{7}$ & $6.26 \times 10^{6}$ & $2.16 \times 10^{6}$ \\
0.6 & $3.23 \times 10^{6}$ & $6.2 \times 10^{5}$ & $1.06 \times 10^{5}$ \\
1 & $1.58 \times 10^{5}$ & $<10^{5}$ & $<10^{5}$ \\
1.8 & $<10^{5}$ & $<10^{5}$ & $<10^{5}$ \\
\hline
\end{tabular}

Abbreviations: Van, vancomycin; Tat-LipoVan, Tat-functionalized Van-loaded liposomes. the improved antibacterial activity of these particles. These results can be also analyzed with the $\log _{\mathrm{CFU} / \mathrm{mL}}$ values obtained for each sample. For antibiotic concentrations of 0.2 and $0.3 \mu \mathrm{g} / \mathrm{mL}$, the $\log$ values for vancomycin were 7.2 and 6.5 , for functionalized liposomes they were 6.3 and 5 (more than one unit of difference), and for nonfunctionalized liposomes they were 6.8 and 5.8 .

Increasing the antibiotic concentration to $0.7 \mu \mathrm{g} / \mathrm{mL}$ led to the antibacterial activity of vancomycin being augmented considerably, reaching a decrease in the bacteria population of $99 \%$ with respect to the initial values, while with functionalized and nonfunctionalized liposomes, $96 \%-98 \%$ was obtained. Specifically, the use of Tat-functionalized liposomes presented a remarkable inhibitory effect at an antibiotic concentration of $0.6 \mu \mathrm{g} / \mathrm{mL}$, and at higher concentrations, such as $1 \mu \mathrm{g} / \mathrm{mL}$, they completely inhibited bacteria growth. The same occurred with nonfunctionalized liposomes, in which at a concentration of $1 \mu \mathrm{g} / \mathrm{mL}$ they totally inhibited bacteria growth. Functionalized liposomes presented higher antibacterial activity, as they combined the double-cellpenetrating properties of the Tat peptide and the $\mathrm{pH}$-sensitive liposomes. The MICs obtained for Tat-functionalized and nonfunctionalized liposomes loaded with antibiotic were $1 \mu \mathrm{g} / \mathrm{mL}$, and for free vancomycin it was $1.8 \mu \mathrm{g} / \mathrm{mL}$.

\section{MRSA}

As has been reported in many studies, ${ }^{21-23}$ MRSA presents high resistance to methicillin, a fact that can be easily observed in the first graph, where all of the samples with antibiotic grew without presenting any remarkable delay in the log phase of the growth curve (Figure 4A). By comparing the antibacterial effect of each particle type for the same concentration of antibiotic (Figure 4), a remarkable increase in bacteria-inhibitory growth effect of Tat-functionalized liposomes can be observed with respect to the free antibiotic. For the first two antibiotic concentrations ( 0.1 and $0.5 \mu \mathrm{g} / \mathrm{mL}$ ), the antibacterial effect of all the particles was similar. However, at a concentration of $0.9 \mu \mathrm{g} / \mathrm{mL}$, a significant delay in the log phase of the bacteria-growth curve can be observed for Tat-functionalized particles with respect to the other two options. For a concentration of $1.7 \mu \mathrm{g} / \mathrm{mL}$, the delay was considerably more with respect to the nonfunctionalized liposomes and free methicillin, which led to a total inhibition of bacteria growth at higher concentrations. Growth curves obtained from free methicillin and nonfunctionalized liposomes became close to each other, showing the one with liposomes the lowest values of $\mathrm{OD}$, until an antibiotic concentration of $3.3 \mu \mathrm{g} / \mathrm{mL}$, when 

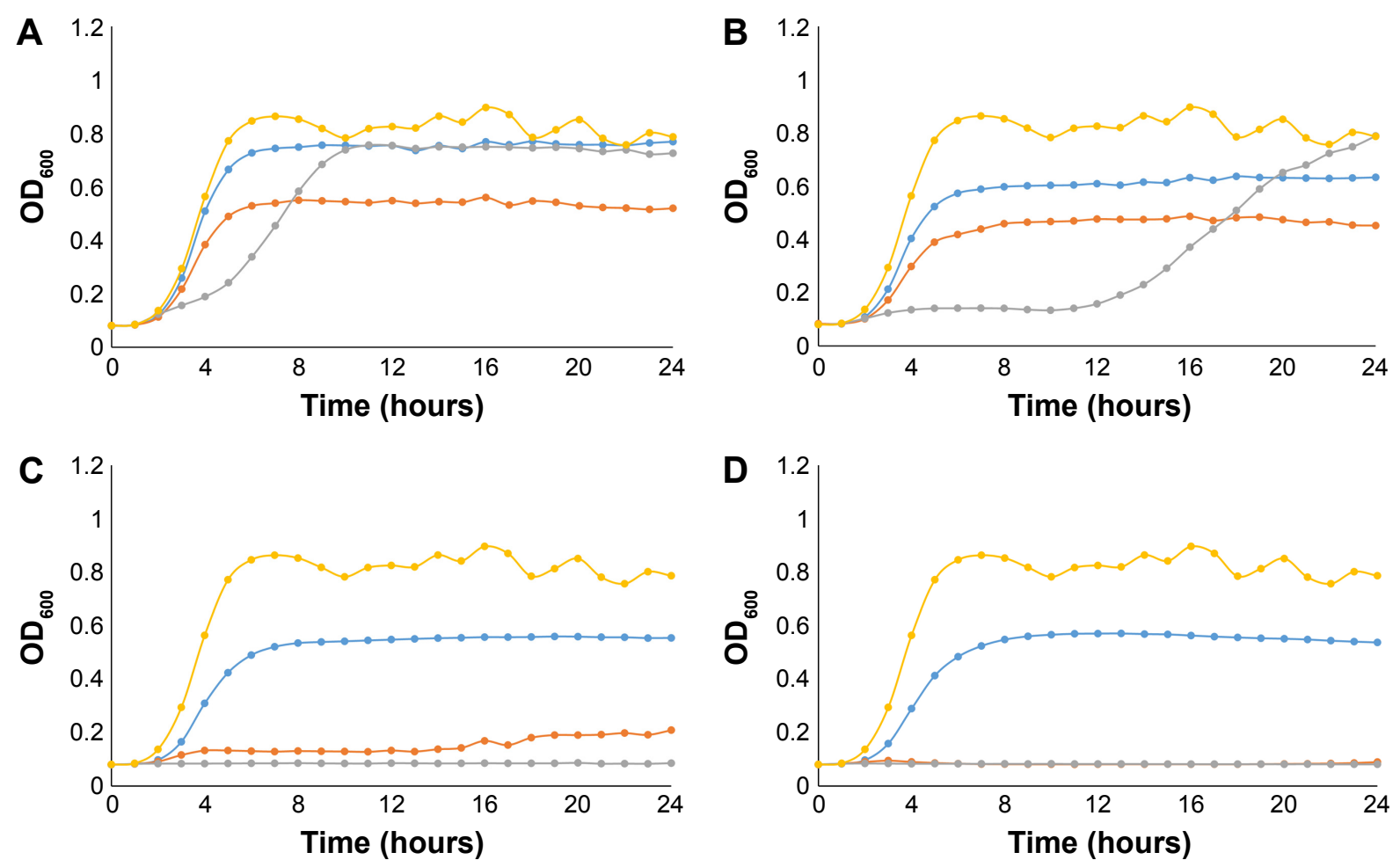

$$
\rightarrow \text { Met } \rightarrow \text { LipoMet } \rightarrow \text { Tat-LipoMet } \rightarrow \text { Control }
$$

Figure 4 Met-resistant Staphylococcus aureus treated with Met, Tat-LipoMet, and LipoMet.

Notes: Antibiotic concentrations of (A) $0.9 \mu \mathrm{g} / \mathrm{mL}$, (B) $1.7 \mu \mathrm{g} / \mathrm{mL}$, (C) $3.3 \mu \mathrm{g} / \mathrm{mL}$, and (D) $5 \mu \mathrm{g} / \mathrm{mL}$. Data presented as means ( $\mathrm{n}=3$ ).

Abbreviations: Met, methicillin; Tat-LipoMet, Tat-functionalized Met-loaded liposomes; OD, optical density.

the nonfunctionalized liposomes showed great antibacterial activity with respect to free methicillin.

This improvement in MRSA treatment could be associated not only with the capability of fusogenic liposomes to fuse with the bacteria membrane and release the antibiotic but also could be due to the accumulation of the liposomes where the bacteria are located, leading to a major localized concentration of the antibiotic. ${ }^{8,24}$ Results showed that the MIC for the Tat-functionalized liposomes was $3.3 \mu \mathrm{g} / \mathrm{mL}$, for nonfunctionalized liposomes it was $5 \mu \mathrm{g} / \mathrm{mL}$, and for the free antibiotic it was $>5 \mu \mathrm{g} / \mathrm{mL}$. The same model used for vancomycin and $S$. pneumoniae was used here to quantify the OD measurements with MRSA (Table 3).
For MRSA treatment, the highest values for all the different parameters were obtained by administering free antibiotic to the sample. This shows the effectiveness of methicillin for fighting these bacteria. The most remarkable value was the increase in lag time for Tat-functionalized liposomes at an antibiotic concentration of $1.7 \mu \mathrm{g} / \mathrm{mL}$ : more than 9 hours in comparison with the lag time obtained with an antibiotic concentration of $0.9 \mu \mathrm{g} / \mathrm{mL}$. Such data provide significant evidence for the antibacterial effect of these particles.

Even the increase in lag time for the nonfunctionalized liposomes was not close to the values obtained with functionalized liposomes. Impressively, at an antibiotic concentration of $3.3 \mu \mathrm{g} / \mathrm{mL}$, bacteria growth was totally inhibited for both

Table 3 Parameters calculated for the growth-curve model for Met-resistant Staphylococcus aureus

\begin{tabular}{|c|c|c|c|c|c|c|c|c|c|}
\hline \multirow[t]{2}{*}{$\mu g / m L$} & \multicolumn{3}{|c|}{ Asymptote } & \multicolumn{3}{|c|}{ Specific growth rate $(\mu)$, hours } & \multicolumn{3}{|c|}{ Lag time $(\lambda)$, hours } \\
\hline & Met & LipoMet & Tat-LipoMet & Met & LipoMet & Tat-LipoMet & Met & LipoMet & Tat-LipoMet \\
\hline 0.9 & 0.77 & 0.56 & 0.76 & 0.19 & 0.23 & 0.1 & 1.43 & 1.64 & 1.64 \\
\hline 1.7 & 0.64 & 0.49 & 0.79 & 0.15 & 0.09 & 0.07 & 1.36 & 1.06 & 10.82 \\
\hline 3.3 & 0.57 & 0.21 & 0.086 & 0.13 & - & - & 1.68 & - & - \\
\hline 5 & 0.57 & 0.09 & 0.083 & 0.13 & - & - & I.74 & - & - \\
\hline
\end{tabular}

Abbreviations: Met, methicillin; Tat-LipoMet, Tat-functionalized Met-loaded liposomes. 
particle types. The maximum OD values obtained for both liposomes at that concentration were around $0.2-0.1$.

With regard to results obtained for methicillin and vancomycin, the free antibiotic presented higher values for asymptotic values and also for specific growth rate, showing a poor antibacterial effect. The opposite happened with the lag-time parameter, where the highest values were achieved by functionalized liposomes, showing their bacterial growthinhibitory effect.

Tables 1 and 3 show asymptote values from 0.08 to 0.95 . With regard to specific growth rate, higher values were obtained with methicillin, showing higher resistance of MRSA to methicillin than that from S. pneumoniae to vancomycin. Nevertheless, the Tat-functionalized liposomes worked better for MRSA, as can be seen in the log-phase delay, as noted earlier (Table 3). For S. pneumoniae, there was not any remarkable delay in the bacteria-growth curve.

As with $S$. pneumoniae, more accurate results were obtained with the colony-counting assay. As can be seen in Figure 5, for the minimum concentration of antibiotic, there was not any remarkable difference between any of the three treatment options, while increasing the antibiotic concentration caused higher antibacterial activity for the Tat-functionalized liposomes, followed by the liposomes loaded with the antibiotic. As expected, MRSA had almost the same antibiotic resistance for all the concentrations of free antibiotic tested in this assay. With the data obtained, the antibacterial properties of these liposomes became more remarkable, providing a solution for treating MRSA where conventional antibiotic strategies fail. When we increased

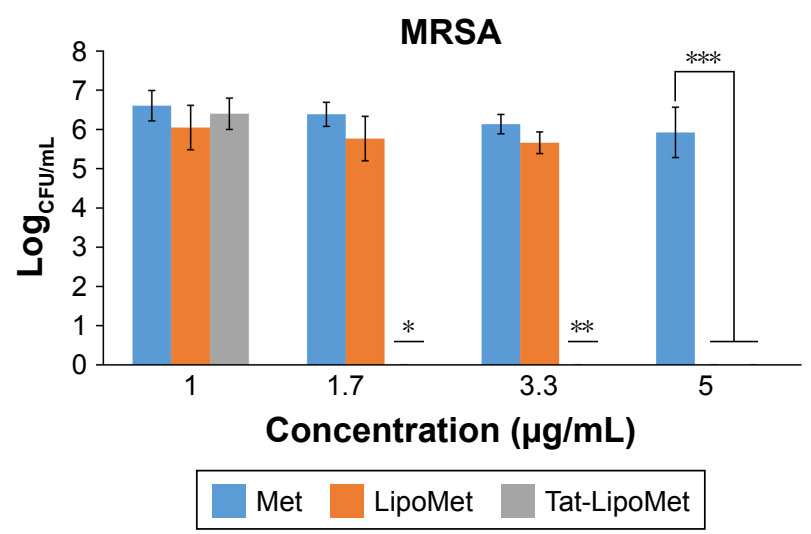

Figure 5 Colony-forming units (CFU) of bacteria after treatment with free Met, LipoMet, and Tat-LipoMet for 8 hours.

Notes: $* P<0.05$ versus free Met and LipoMet $(1.7 \mu \mathrm{g} / \mathrm{mL})$; $* * P<0.05$ versus free Met $(3.3 \mu \mathrm{g} / \mathrm{mL}) ; * * * P<0.05$ versus free Met $(5 \mu \mathrm{g} / \mathrm{mL})$.

Abbreviations: Met, methicillin; Tat-LipoMet, Tat-functionalized Met-loaded liposomes; MRSA, Met-resistant Staphylococcus aureus.
Table 4 Colony-forming units (CFU) for particles and concentrations

\begin{tabular}{llll}
\hline$\mu \mathrm{g} / \mathrm{mL}$ & CFU $/ \mathrm{mL}$ & & \\
\cline { 2 - 4 } & Met & LipoMet & Tat-LipoMet \\
\hline $\mathrm{I}$ & $4.05 \times 10^{6}$ & $1.12 \times 10^{6}$ & $2.52 \times 10^{6}$ \\
1.7 & $2.43 \times 10^{6}$ & $5.86 \times 10^{5}$ & $<10^{5}$ \\
3.3 & $1.36 \times 10^{6}$ & $4.58 \times 10^{5}$ & $<10^{5}$ \\
5 & $8.39 \times 10^{5}$ & $<10^{5}$ & $<10^{5}$ \\
\hline
\end{tabular}

Abbreviations: Met, methicillin; Tat-LipoMet, Tat-functionalized Met-loaded liposomes.

the antibiotic concentration from 1 to $1.7 \mu \mathrm{g} / \mathrm{mL}$, the bacteria population decreased $40 \%$ for free methicillin, around $50 \%$ for nonfunctionalized liposomes, and a remarkable $96 \%$ for the functionalized liposomes (Table 4). For these assays, as for the growth curve, the MIC obtained with liposomes loaded with methicillin was $5 \mu \mathrm{g} / \mathrm{mL}$, while the MIC for Tat-functionalized liposomes obtained was $1.7 \mu \mathrm{g} / \mathrm{mL}$. It was not possible to calculate the MIC for the free methicillin in these assays, since it did not reduce bacteria growth at all.

\section{E. coli}

Lastly, studies performed with E. coli showed unexpected results, as seen in Figure 6. These graphs show that our particles presented the same antibacterial activity as the free antibiotic. In previous studies, fusogenic particles have presented higher antibacterial activity for Gram-negative bacteria; therefore, our particles should have presented a higher inhibitory effect than the use of the free antibiotic. However, the following graph (Figure 6) showed that for antibiotic concentrations of $1-10 \mu \mathrm{g} / \mathrm{mL}$, the growth curves of all the samples treated with ampicillin or functionalized or nonfunctionalized liposomes loaded with antibiotics look exactly the same. This means that all three different treatments were ineffective for this bacteria at those antibiotic concentrations. When the concentration was increased to 33 or $50 \mu \mathrm{g} / \mathrm{mL}$, the results did not show such a remarkable difference. It seems that the option that presented more growth-inhibitory effect was the use of nonfunctionalized liposomes, followed closely by free antibiotic and functionalized liposomes. To understand the results obtained and determine a mechanism of action (such as by examining the ability of the particles to penetrate bacteria), additional studies should be performed.

The parameters obtained for the modified Gompertz model are presented in Table 5. For the asymptote parameter, the values are similar for all the treatments, as they are for specific growth rate and lag time. The results presented 

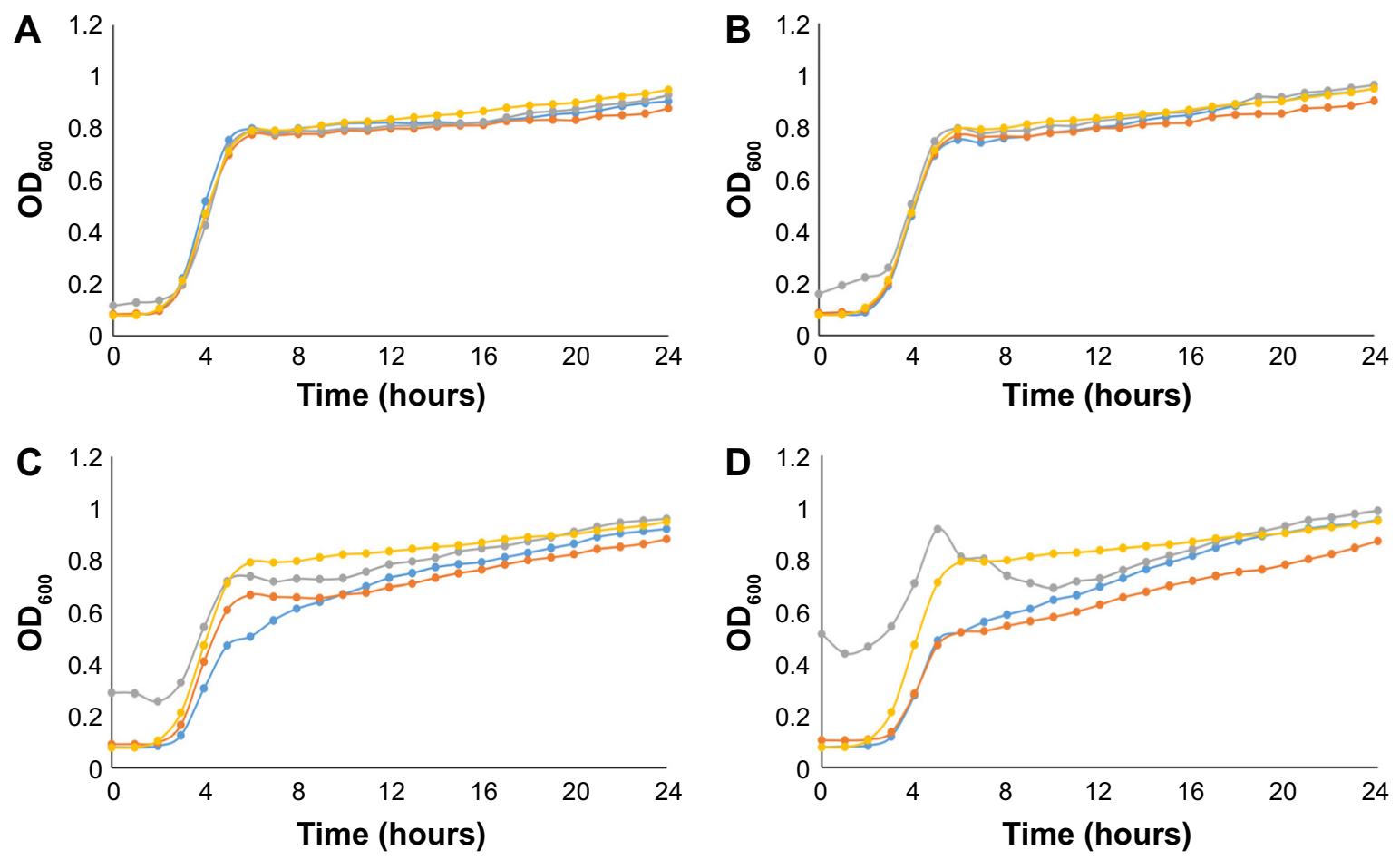

$$
\rightarrow \text { Amp } \rightarrow \text { LipoAmp } \rightarrow \text { Tat-LipoAmp } \rightarrow \text { Control }
$$

Figure 6 Escherichia coli treated with Amp, Tat-LipoAmp, and LipoAmp.

Notes: Antibiotic concentrations of (A) I $\mu \mathrm{g} / \mathrm{mL}$, (B) $10 \mu \mathrm{g} / \mathrm{mL}$, (C) $33 \mu \mathrm{g} / \mathrm{mL}$ and (D) $50 \mu \mathrm{g} / \mathrm{mL}$. Data presented as means ( $\mathrm{n}=3$ ).

Abbreviations: Amp, ampicillin; Tat-LipoAmp, Tat-functionalized Amp-loaded liposomes; OD, optical density.

in this table confirm what was observed with Figure 6: the use of functionalized and nonfunctionalized liposomes does not show an improvement in treatment of multidrugresistant E. coli.

When these results are compared with those obtained for S. pneumoniae (Table 1) and MRSA (Table 3), it can be concluded that the most remarkable increase in antibacterial activity was obtained with the liposomes loaded with methicillin, with great decreases in asymptote-parameter values and specific growth rates. Followed by liposomes loaded with vancomycin for $S$. pneumoniae, a less effective treatment was with liposomes loaded with ampicillin for multidrug-resistant E. coli.

\section{Live/dead assays}

\section{S. pneumoniae}

Data obtained from the live/dead assays highlighted again that the antibacterial activity of the Tat-functionalized liposomes was much higher than the antibacterial activity of free vancomycin (Figure 7). Specifically, at an antibiotic concentration of $0.6 \mu \mathrm{g} / \mathrm{mL}$, the control sample and that containing the free added antibiotic presented almost the same appearance, demonstrating that most of the bacteria were still alive (green dots); therefore, such results highlight the inefficiency of using the free antibiotic. Just the opposite happened after administration of the Tatfunctionalized liposomes with the same concentration of

Table 5 Parameters calculated for the growth-curve model for Escherichia coli

\begin{tabular}{|c|c|c|c|c|c|c|c|c|c|}
\hline \multirow[t]{2}{*}{$\mu g / m L$} & \multicolumn{3}{|c|}{ Asymptote } & \multicolumn{3}{|c|}{ Specific growth rate $(\mu)$, hours } & \multicolumn{3}{|c|}{ Lag time $(\lambda)$, hours } \\
\hline & Amp & LipoAmp & Tat-LipoAmp & Amp & LipoAmp & Tat-LipoAmp & Amp & LipoAmp & Tat-LipoAmp \\
\hline I & 0.91 & 0.88 & 0.92 & 0.27 & 0.25 & 0.26 & 2.13 & 2.19 & 2.3 \\
\hline 10 & 0.94 & 0.9 & 0.96 & 0.25 & 0.25 & 0.24 & 2.22 & 2.16 & 1.93 \\
\hline 33 & 0.92 & 0.88 & 0.96 & 0.17 & 0.22 & 0.2 & 2.26 & 2.22 & 1.28 \\
\hline 50 & 0.95 & 0.87 & 0.98 & 0.18 & 0.17 & 0.19 & 2.4 & 2.22 & 0.13 \\
\hline
\end{tabular}

Abbreviations: Amp, ampicillin; Tat-LipoAmp, Tat-functionalized Amp-loaded liposomes. 


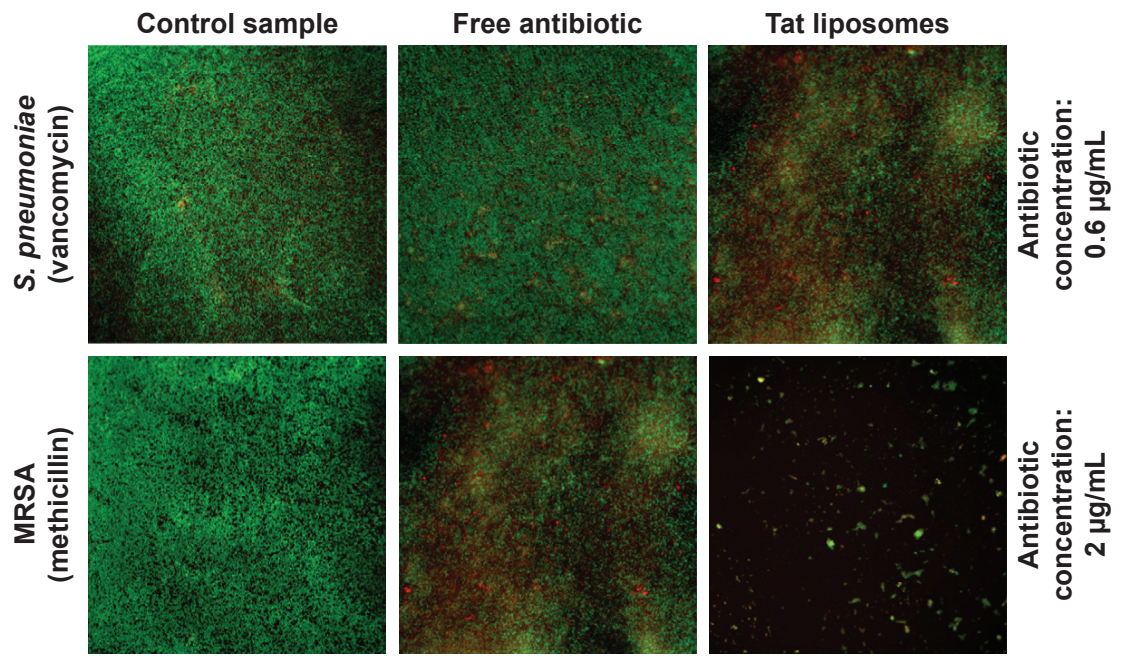

Figure 7 Live/dead assays with Streptococcus pneumoniae and methicillin-resistant Staphylococcus aureus (MRSA).

Notes: Live bacteria in green, and dead bacteria in red. Magnification I0x. Antibiotic concentrations of $0.6 \mu \mathrm{g} / \mathrm{mL}$ for vancomycin and $2 \mu \mathrm{g} / \mathrm{mL}$ for methicillin.

antibiotic. In these samples, a significant proportion of the bacteria had died (red dots) compared with the control sample. This result confirmed the improved antibacterial properties of the Tat-functionalized liposomes versus free vancomycin.

\section{MRSA}

Figure 7 supports the previous experimental results concerning the remarkable antibacterial activity of Tat-functionalized liposomes loaded with methicillin. Fluorescence images illustrate that with an antibiotic concentration of $2 \mu \mathrm{g} / \mathrm{mL}$, with free methicillin most of the bacteria population were still alive, while with the Tat-functionalized liposomes, the reduction in the bacteria population was much more severe, as almost all bacteria in the samples died. The use of Tat-functionalized liposomes could thus be considered a promising new way to fight MRSA bacteria.

\section{Cytotoxicity assays}

\section{Vancomycin}

The results obtained for astrocytes with all of the combinations (Tat alone, Tat-functionalized liposomes loaded/not loaded with vancomycin, and free vancomycin), presented in Figure 8 showed a high percentage of cell viability. However, in both cases, with astrocytes and endothelial cells a decrease in percentage cell viability when Tat and vancomycin were used alone can be observed. As has been reported previously, the use of liposomes decreases the cytotoxicity of the drug (which usually presents some cytotoxicity), as it is carried inside the cell and only releases drug in the presence of
A

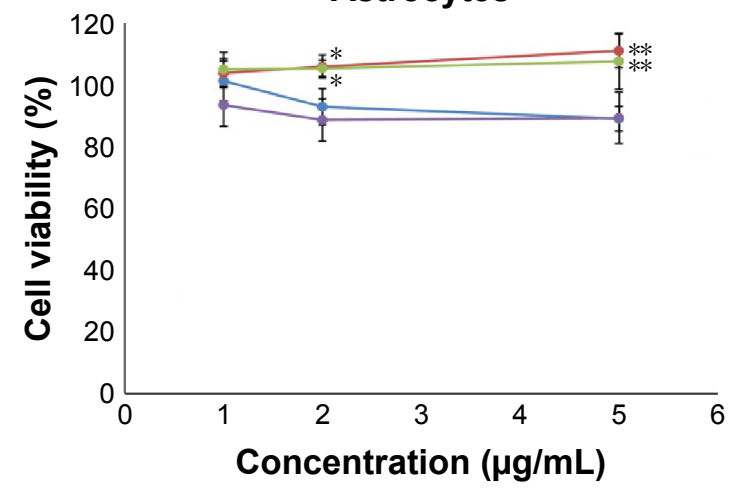

B

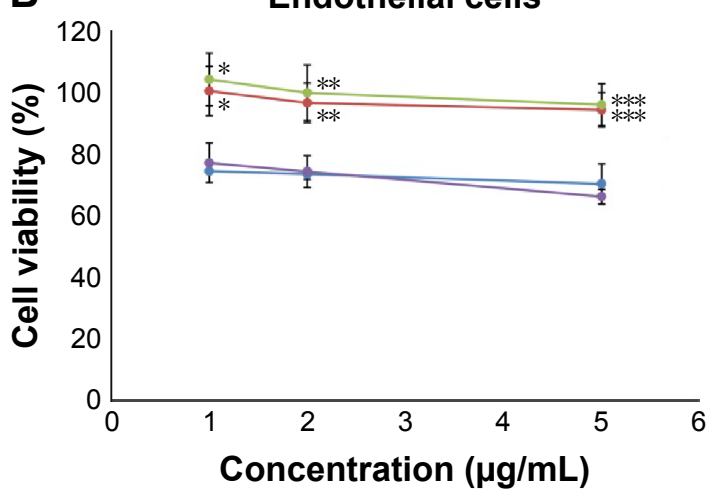

$$
\leftrightarrow \text { Van } \rightarrow \text { Tat-LipoVan } \rightarrow \text { Tat-Lipo } \quad \bullet \text { Tat }
$$

Figure 8 Cell viability after treatment with Van, Tat-LipoVan, Tat-Lipo, and Tat alone.

Notes: (A) Astrocyte cells after 24 hours. $* P<0.05$ versus free $V$ an $(2 \mu g / \mathrm{mL}) ; * * P<0.05$ versus free $\operatorname{Van}(5 \mu \mathrm{g} / \mathrm{mL})$. (B) Endothelial cells after 24 hours. $* P<0.05$ versus free Van $(I \mu \mathrm{g} / \mathrm{mL}) ; * * P<0.05$ versus free $\operatorname{Van}(2 \mu \mathrm{g} / \mathrm{mL}) ; * * * P<0.05$ versus free $V a n(5 \mu \mathrm{g} / \mathrm{mL})$.

Abbreviations: Van, vancomycin; Tat-LipoVan, Tat-functionalized Van-loaded liposomes. 
A

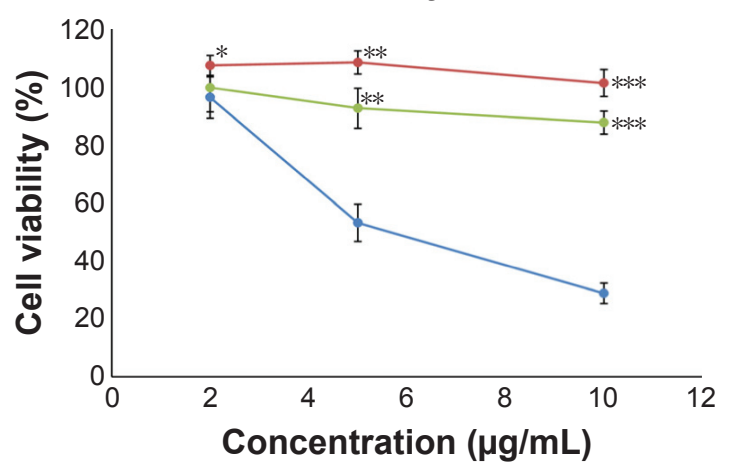

B Endothelial cells

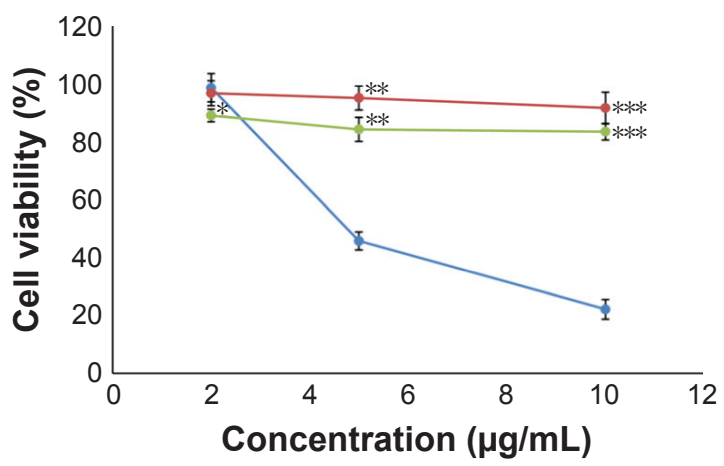

$\rightarrow$ Met $\rightarrow$ Tat-LipoMet $\quad \rightarrow$ LipoMet

Figure 9 Cell viability after treatment with Met, Tat-LipoMet, and LipoMet.

Notes: (A) Astrocytes after 24 hours. $* P<0.05$ versus free Met $(2 \mu \mathrm{g} / \mathrm{mL}) ; * * P<0.05$ versus free Met $(5 \mu \mathrm{g} / \mathrm{mL})$; *** $P<0.05$ versus free Met $(10 \mu \mathrm{g} / \mathrm{mL})$. (B) Endothelial cells after 24 hours. $* P<0.05$ versus free Met $(2 \mu \mathrm{g} / \mathrm{mL}) ; * * P<0.05$ versus free Met $(5 \mu \mathrm{g} / \mathrm{mL})$; ${ }^{* * *} P<0.05$ versus free Met $(10 \mu g / \mathrm{mL})$.

Abbreviations: Met, methicillin; Tat-LipoMet, Tat-functionalized Met-loaded liposomes.

the target molecules: in this case, bacteria. Tat previously presented some toxicity at higher concentrations with HeLa cells. ${ }^{25}$ This is because it presents lower cytotoxicity when attached to a liposome, which could be because then it is in a concentrated form where the liposomes are located, and liposomes have no affinity with astrocytes or endothelial cells. Therefore, they do not attach to the cells, so the Tat peptide will not cause damage. Antibiotic loading inside the nonfunctionalized and functionalized liposomes did not affect the cytotoxicity of the particles.

\section{Methicillin}

Results obtained with functionalized and nonfunctionalized liposomes loaded with methicillin and free methicillin were quite similar for astrocytes and endothelial cells (Figure 9).
Methicillin alone presented higher toxicity at high concentrations for both the groups of cells, which is a clear limitation for its use in fighting brain diseases. Nevertheless, by loading the antibiotic inside the liposomes, cytotoxicity was exceptionally reduced and cell viability increased to around $60 \%$, which is a remarkable improvement. Similar cell viability was obtained with Tat-functionalized and nonfunctionalized liposomes loaded with antibiotics, with functionalized liposomes showing higher cell-viability values, but not with a significant difference from the nonfunctionalized ones.

\section{Ampicillin}

The cytotoxicity of ampicillin compared with functionalized and nonfunctionalized liposomes loaded with this antibiotic was also calculated in this study (Figure 10). The
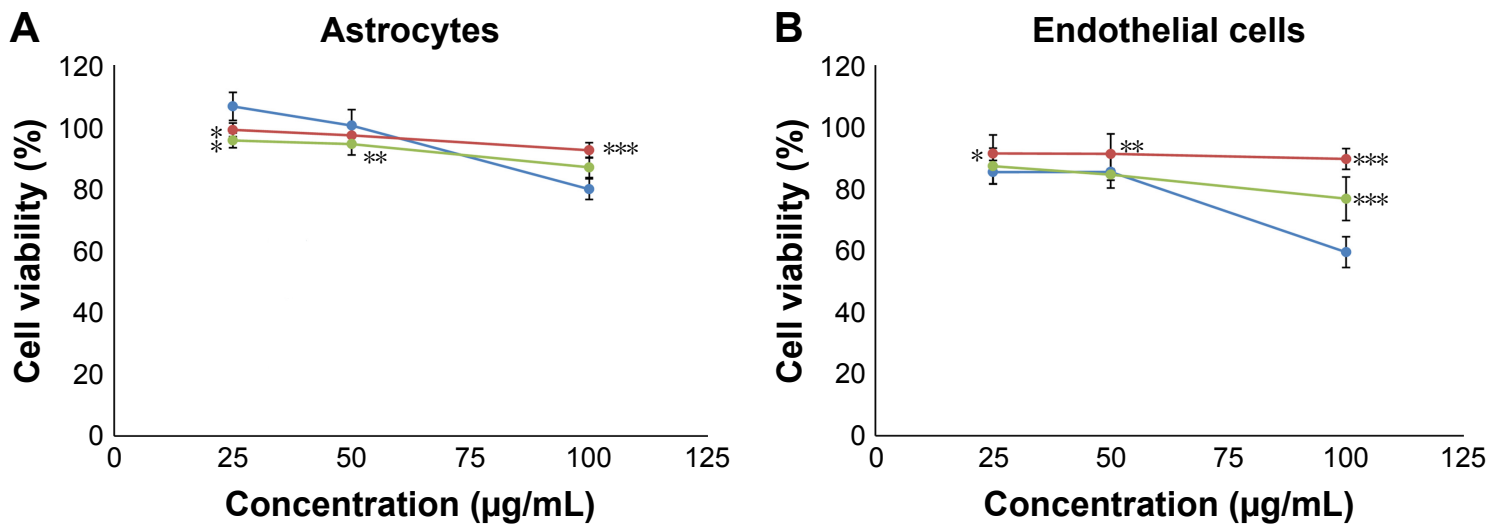

$\rightarrow$ Amp $\rightarrow$ Tat-LipoAmp $\rightarrow$ LipoAmp

Figure 10 Cell viability after treatment with Amp, Tat-LipoAmp, and LipoAmp.

Notes: (A) Astrocyte cells after 24 hours. $* P<0.05$ versus free Amp $(25 \mu \mathrm{g} / \mathrm{mL})$; $* * P<0.05$ versus free Amp $(50 \mu \mathrm{g} / \mathrm{mL})$; $* * * P<0.05$ versus free Amp $(100 \mu g / \mathrm{mL})$. (B) Endothelial cells after 24 hours. $* P<0.05$ versus free Amp $(25 \mu \mathrm{g} / \mathrm{mL})$; $* * P<0.05$ versus free Amp $(50 \mu \mathrm{g} / \mathrm{mL})$; $* * * P<0.05$ versus free Amp $(100 \mu \mathrm{g} / \mathrm{mL})$.

Abbreviations: Amp, ampicillin; Tat-LipoAmp, Tat-functionalized Amp-loaded liposomes. 
results obtained for both types of cells were similar, showing more cytotoxicity for endothelial cells than astrocytes. At higher concentrations of about $100 \mu \mathrm{g} / \mathrm{mL}$, the free antibiotic presented more cytotoxicity, while functionalized and nonfunctionalized liposomes did not present any significant increase in their cytotoxicity.

\section{Conclusion}

The aim of this study was to demonstrate the ability of fusogenic liposomes loaded with antibiotics and functionalized with cell-penetrating peptides $\left(\mathrm{Tat}_{47-57}\right)$ to kill the main bacteria that cause meningitis. The capability of these functionalized liposomes to fight not only common bacteria, such as MRSA, but also one of the main bacteria that cause meningitis, S. pneumoniae, was shown here for the first time via antibacterial studies and live/dead assays. Remarkable results were obtained for MRSA by using Tat-functionalized liposomes loaded with methicillin, obtaining an MIC of about $1.7 \mu \mathrm{g} / \mathrm{mL}$. In addition, the use of nonfunctionalized liposomes loaded with methicillin demonstrated a remarkable improvement in comparison with free methicillin delivery, obtaining an MIC of just $3.3 \mu \mathrm{g} / \mathrm{mL}$. The Tat-functionalized liposomes presented the highest antibacterial activity in all the assays, followed by nonfunctionalized liposomes and free antibiotic. Therefore, it can be concluded that the combination of fusogenic liposomes and Tat peptides improved localized antibiotic release by administering the antibiotic directly inside bacterial cells. This not only means increased efficiency in killing bacteria but also a decrease in mammalian cell toxicity.

Cytotoxicity assays with endothelial cells and astrocytes were performed, showing a remarkable increase in percentage cell viability using functionalized and nonfunctionalized liposomes in comparison with free antibiotics. This behavior was attributed to the affinity of fusogenic liposomes to interact just with bacteria and not with mammalian cells, which are part of the blood-brain barrier, which implies that the antibiotic is released directly inside or in-close contact with the bacteria without being spread around where it can affect healthy cells. In this manner, this study provides significant promising evidence for the continued study of the novel Tat-functionalized liposomes for treating bacteria that are antibiotic-resistant and in the brain.

\section{Acknowledgment}

The authors would like to thank Northeastern University for funding.

\section{Disclosure}

The authors report no conflicts of interest in this work.

\section{References}

1. Whitney CG, Farley MM, Hadler J, et al. Increasing prevalence of multidrug-resistant Streptococcus pneumoniae in the United States. N Engl J Med. 2000;343:1917-1924.

2. Forier K, Raemdonck K, De Smedt SC, Demeester J, Coenye T, Braeckmans K. Lipid and polymer nanoparticles for drug delivery to bacterial biofilms. J Control Release. 2014;190:607-623.

3. Meers $\mathrm{P}$, Neville M, Malinin V, et al. Biofilm penetration, triggered release and in vivo activity of inhaled liposomal amikacin in chronic Pseudomonas aeruginosa lung infections. J Antimicrob Chemother. 2008; 61:859-868.

4. Liechty WB, Kryscio DR, Slaughter BV, Peppas NA. Polymers for drug delivery systems. Annu Rev Chem Biomol Eng. 2010;1:149-173.

5. Guzman M, Dille J, Godet S. Synthesis and antibacterial activity of silver nanoparticles against Gram-positive and Gram-negative bacteria. Nanomedicine. 2012;8:37-45.

6. Bahar AA, Ren D. Antimicrobial peptides. Pharmaceuticals. 2013;6: 1543-1575.

7. Hazra M, Singh SK, Ray S. Surface modification of liposomal vaccines by peptide conjugation. $J$ PharmSciTech. 2011;1:41-47.

8. Liu X, Huang G. Formation strategies, mechanism of intracellular delivery and potential clinical applications of $\mathrm{pH}$-sensitive liposomes. Asian J Pharm Sci. 2013;8:319-328.

9. Gomes-da-Silva LC, Fonseca NA, Moura V, de Lima MC, Simões S, Moreira JN. Lipid-based nanoparticles for siRNA delivery in cancer therapy: paradigms and challenges. Acc Chem Res. 2012;45: 1163-1171.

10. Vidal M, Hoekstra D. In vitro fusion of reticulocyte endocytic vesicles with liposomes. J Biol Chem. 1995;270:17823-17829.

11. Nicolosi D, Scalia M, Nicolosi VM, Pignatello R. Encapsulation in fusogenic liposomes broadens the spectrum of action of vancomycin against Gram-negative bacteria. Int J Antimicrob Agents. 2010;35:553-558.

12. Pignatello R, Nicolosi D, Nicolosi VM. Fusogenic liposomes as new carriers to enlarge the spectrum of action of antibiotic drugs against Gram-negative bacteria. In: Méndez-Vilas A, editor. Science Against Microbial Pathogens: Communicating Current Research and Technological Advances. Badajoz, Spain: Formatex Research Center; 2011: $52-60$.

13. Stalmans S, Bracke N, Wynendaele E, et al. Cell-penetrating peptides selectively cross the blood-brain barrier in vivo. PLoS One. 2015; 10:e0139652.

14. Tunkel AR, Hartman BJ, Kaplan SL, et al. Practice guidelines for the management of bacterial meningitis. Clin Infect Dis. 2004;39: $1267-1284$.

15. Zong T, Mei L, Gao H, et al. Synergistic dual-ligand doxorubicin liposomes improve targeting and therapeutic efficacy of brain glioma in animals. Mol Pharm. 2014;11:2346-2357.

16. El-Ashry SM, Belal F, El-Kerdawy MM, El Wasseef DR. Spectrophotometric determination of some phenolic antibiotics in dosage forms. Microchim Acta. 2000;135:191-196.

17. Smith JW, de Grey GE, Patel VJ. Spectrophotometric determination of ampicillin. Analyst. 1967;92:247-252.

18. Weaver WJ, Reschke RF. Spectrophotometric determination of sodium 2,6 dimethoxyphenyl penicillin monohydrate (methicillin). JPharm Sci. $1963 ; 52: 362-364$.

19. Chakraborty SP, Sahu SK, Pramanik P, Roy S. In vitro antimicrobial activity of nanoconjugated vancomycin against drug resistant Staphylococcus aureus. Int J Pharm. 2013;436:659-676.

20. Ellbogen MH, Olsen KM, Gentry-Nielsen MJ, Preheim LC. Efficacy of liposome-encapsulated ciprofloxacin compared with ciprofloxacin and ceftriaxone in a rat model of pneumococcal pneumonia. $J$ Antimicrob Chemother. 2003;51:83-91. 
21. Diep BA, Gill SR, Chang RF, et al. Complete genome sequence of USA300, an epidemic clone of community-acquired meticillin-resistant Staphylococcus aureus. Lancet. 2006;367:731-739.

22. Baba T, Takeuchi F, Kuroda M, et al. Genome and virulence determinants of high virulence community-acquired MRSA. Lancet. 2002; 359:1819-1827.

23. Klevens RM, Morrison MA, Nadle J, et al. Invasive methicillinresistant Staphylococcus aureus infections in the United States. JAMA. 2007;298:1763-1771.
24. Cordeiro C, Wiseman DJ, Lutwyche P, et al. Antibacterial efficacy of gentamicin encapsulated in $\mathrm{pH}$-sensitive liposomes against an in vivo Salmonella enterica serovar Typhimurium intracellular infection model. Antimicrob Agents Chemother. 2000;44:533-539.

25. Takeshima K, Chikushi A, Lee KK, Yonehara S, Matsuzaki K. Translocation of analogues of the antimicrobial peptides magainin and buforin across human cell membranes. J Biol Chem. 2003;278:1310-1315.
International Journal of Nanomedicine

\section{Publish your work in this journal}

The International Journal of Nanomedicine is an international, peerreviewed journal focusing on the application of nanotechnology in diagnostics, therapeutics, and drug delivery systems throughout the biomedical field. This journal is indexed on PubMed Central, MedLine, CAS, SciSearch $®$, Current Contents $\AA /$ Clinical Medicine,

\section{Dovepress}

Journal Citation Reports/Science Edition, EMBase, Scopus and the Elsevier Bibliographic databases. The manuscript management system is completely online and includes a very quick and fair peer-review system, which is all easy to use. Visit http://www.dovepress.com/ testimonials.php to read real quotes from published authors.

Submit your manuscript here: http://www.dovepress.com/international-journal-of-nanomedicine-journal 